\title{
Long-Term Effect of Four Surgical Periodontal Therapies and One Non-Surgical Therapy: A Systematic Review and Meta-Analysis
}

\author{
James Mailoa, ${ }^{*}$ Guo-Hao Lin, ${ }^{*}$ Vahid Khoshkam, ${ }^{\dagger}$ Mark MacEachern, ${ }^{\ddagger}$ Hsun-Liang Chan, ${ }^{*}$ and \\ Hom-Lay Wang*
}

Background: The aim of this systematic review is to evaluate the long term ( $\geq 2$ years) effect of four surgical and nonsurgical therapies in treating periodontal disease.

Methods: An electronic search of four databases and a hand search of peer-reviewed journals for relevant articles were conducted. Prospective human controlled clinical trials were included that compared surgical therapy to non-surgical therapy in $\geq 10$ patients diagnosed with chronic periodontitis with a follow-up period of $\geq 2$ years and that reported change in probing depth (PD) and clinical attachment level (CAL) after the therapy. Random effect meta-analysis was performed to compare the outcome of surgical and non-surgical therapy in shallow, moderate, and deep PD.

Results: Eight human prospective clinical trials were included. In 1- to 3-mm PD, scaling and root planing (SRP), modified Widman flap (MWF), and osseous surgery (OS) resulted in $23.2 \%, 39.4 \%$, and $61.39 \%$ CAL loss, respectively; $\mathrm{SRP}, \mathrm{MWF}$, and OS resulted in increased mean PD of $2.5 \%$, $3.3 \%$, and $6.3 \%$, respectively. In $4-$ to $6-\mathrm{mm} \mathrm{PD}$, SRP, MWF, and OS resulted in $8.4 \%, 6.5 \%$, and $5.22 \%$ CAL gain, respectively; SRP, MWF, and OS resulted in $18.7 \%, 25.4 \%$, and $30.8 \% \mathrm{PD}$ reduction, respectively. In PD $\geq 7 \mathrm{~mm}$, SRP, MWF, and OS resulted in 9.8\%, 14.2\%, and 9.38\% CAL gain, respectively; SRP, MWF, and OS resulted in mean PD reduction of $21.6 \%, 33.1 \%$, and $42.8 \%$, respectively.

Conclusions: Surgical therapy had significantly more CAL loss than non-surgical therapy in shallow PD. In moderate PD, MWF had significantly more PD reduction than SRP, and there was significantly less CAL gain with surgical therapy. In deep PD, OS had significantly higher PD reduction than SRP. J Periodontol 2015;86:1150-1158.

\section{KEY WORDS}

Longitudinal studies; periodontal debridement; periodontitis; review, systematic root planing; surgical flaps.

\footnotetext{
* Department of Periodontics and Oral Medicine, University of Michigan School of Dentistry, Ann Arbor, MI

$\dagger$ Herman Ostrow School of Dentistry, University of Southern California, Los Angeles, CA.

$\ddagger$ A. Alfred Taubman Health Sciences Library, University of Michigan.
}

2 eriodontitis is an inflammation of the supporting tissues of the teeth leading to loss of bone and periodontal ligament. ${ }^{1}$ It is accepted that dental plaque micro-organisms existing in the form of biofilms are primary etiologic agents of periodontal diseases. Putative bacterial pathogens associated with periodontal diseases have been identified in subgingival biofilms. ${ }^{2} \mathrm{Re}$ moval of pathogenic biofilms, toxins, and calculus and reestablishment of biologically acceptable root surface are significant in arresting the progression of periodontitis. ${ }^{3}$ This approach can be achieved by non-surgical or surgical periodontal therapy, the efficacy of which in the measurement of surrogate end points has been evaluated in several longterm longitudinal studies ( $\geq 2$ years). ${ }^{4-8}$ It has been assumed that the reported reduction in probing depth (PD) and gain or loss of clinical attachment level (CAL) can be credited to the particular modality of surgical therapy depending on the preoperative PD. ${ }^{5,8}$

A systematic review comparing the effectiveness of surgical and non-surgical debridement showed that in shallow pockets ( 1 to $3 \mathrm{~mm}$ ), no difference in PD reduction was found between treatment modalities, whereas in moderate (4 to $6 \mathrm{~mm}$ ) to deep ( $\geq 7 \mathrm{~mm}$ ) pockets, surgical therapy resulted in greater PD reduction 
than scaling and root planing (SRP). Long-term data showed that surgical and non-surgical procedures are comparable in treating periodontal disease and preventing further attachment loss. ${ }^{9}$ However, longitudinal studies not included in the latter study have suggested that the highest PD reduction and CAL gain could be achieved by both surgical and non-surgical treatment in teeth with moderate $(4$ to $6 \mathrm{~mm}$ ) and deep ( $\geq 7 \mathrm{~mm}$ ) initial PD, but favoring surgical periodontal therapy. ${ }^{5,10}$ Nevertheless, similar PD reduction after non-surgical and surgical treatment has also been reported. ${ }^{8}$ Moreover, less CAL loss was reported in a non-surgical group compared with a surgical group. ${ }^{8}$

When short-term studies ( $\leq 1$ year) were examined, data showed that in moderate initial PD (4 to $6 \mathrm{~mm}$ ), surgical therapy resulted in greater PD reduction, whereas non-surgical therapy resulted in more CAL gain. ${ }^{11,12}$ For teeth with shallow PD (1 to $3 \mathrm{~mm}$ ), both surgical and non-surgical therapy resulted in CAL loss. ${ }^{9}$ Nonetheless, the results in the literature with longer follow-up ( $\geq 2$ years) vary. ${ }^{5,7,8,13}$ Hence, the aim of this study is to evaluate the long-term $(\geq 2$ years) effect of four surgical therapies (modified Widman flap [MWF], osseous surgery [OS], open flap debridement [OFD], and subgingival curettage [SC]) and non-surgical therapy in treating periodontal disease with various PDs.

\section{MATERIALS AND METHODS}

\section{Selection Criteria and Search Strategy}

Prospective, human, controlled clinical trials were included that compared surgical (MWF, OS, OFD, SC) and non-surgical therapy in $\geq 10$ patients diagnosed with chronic periodontitis with a follow-up period of $\geq 2$ years and that reported PD and CAL change after the therapy. Studies published as editorials, letters, or comments; studies not in English; studies with $<2$ years of follow-up; studies featuring regenerative procedures; review articles; animal studies; and case reports/series were excluded.

Searches were conducted in PubMed, Ovid MEDLINE, EMBASE, and Dentistry and Oral Sciences Source by a health science librarian (MM) for the relevant studies published from January 1970 to September 2014. The ENDNOTE library was distributed to the authors for the study selection process.

The search string used for PubMed was as follows: "periodontitis/surgery"[mh] OR (("periodontal diseases"[majr:noexp] OR periodontitis[majr] OR periodontitis[ti] OR periodontal[ti]) AND ("surgery"[sh] OR surgery[ti] OR surgical[ti] OR surgically[ti] OR operation[ti] OR operative[ti])) AND english[la] AND (comparative study[pt] OR "cohort studies"[mh] OR comparison[ti] OR longitudinal[tiab] OR longitudinally[tiab] OR cohort[tiab]) NOT ("animals"[mh]
NOT "humans" [mh]), where $\mathrm{mh}=\mathrm{MeSH}$ term, majr = $\mathrm{MeSH}$ major topic, noexp = without automatic MeSH substitution, $\mathrm{ti}=$ title, $\mathrm{sh}=\mathrm{MeSH}$ subheading, la $=$ language, $\mathrm{pt}=$ publication type, and $\mathrm{ab}=$ abstract.

The search string used for EMBASE was as follows: "periodontitis"/exp/dm_su OR ("periodontal disease"/ de OR "periodontitis"/exp OR periodont*:ti AND ("surgery"/exp OR "dental surgery"/exp OR surger*:ti OR surgic*:ti OR operat*:ti)) AND ("longitudinal study"/exp OR "comparative study"/exp OR "cohort analysis"/exp OR compar*:ti OR longitudinal*:ab,ti OR cohort:ti) AND [english]/lim NOT ([animals]/lim NOT [humans] $/ \mathrm{lim}$ ), where exp = term exploded, $\mathrm{dm}=$ disease management, su = surgery, $/ \mathrm{de}=$ exact search, $\mathrm{ti}=$ title, $\mathrm{ab}=\mathrm{abstract}$, and $\lim =$ limit.

The search string used for Dentistry and Oral Sciences Source was as follows: (SU "periodontal disease" OR SU "periodontitis" OR TI periodont* OR AB periodont*) AND (SU "surgery" OR TI surger* OR TI surgic* OR TI operat*) AND (SU "longitudinal stories" OR TI longitudinal* OR AB longitudinal* OR TI "cohort study" OR AB "cohort study"), where SU = subject, $\mathrm{TI}=$ title, and $\mathrm{AB}=$ abstract.

Furthermore, reference lists from included papers as well as the related systematic review were searched for publications that were not electronically identified. Potential articles were examined in full text by two reviewers (JM and VK), and their eligibility to be included in this study was confirmed after discussion. The level of agreement between the reviewers was calculated with a $\kappa$ value.

\section{Risk of Bias Assessment}

The following criteria of publication bias from the randomized controlled trial (RCT) checklist of the Cochrane Center ${ }^{14}$ and the Consolidated Standards of Reporting Trials (CONSORT) statement ${ }^{15}$ were used: 1) random sequence generation; 2) allocation concealment; 3) blinding of participants and personnel; 4) blinding of outcome assessment; 5) incomplete outcome data; 6) selective outcome reporting; and 7) other sources of bias. The outcome assessment was categorized as: 1) low risk of bias if all key domains had low risk of bias; 2) unclear risk of bias if $\geq 1$ key domains had unclear risk of bias; and 3) high risk of bias if $\geq 1$ key domains had risk of bias.

\section{Data Analyses}

The primary outcome was CAL gain, and the secondary outcome was PD reduction. The results are presented as percentages. For the comparative studies included, the pooled weighted mean and the 95\% confidence interval $(\mathrm{CI})$ of both variables were estimated using a software program. Random effects meta-analyses of the selected studies were applied to

\| Comprehensive Meta-analysis Version 2, Biostat, Englewood, NJ. 
accommodate methodology heterogeneities among studies. The percentages of PD reduction and CAL gain in 1 - to $3-\mathrm{mm}, 4-$ to $6-\mathrm{mm}$, and $\geq 7-\mathrm{mm} \mathrm{PD}$ groups were meta-analyzed and reported based on the different treatment modalities. In addition, the pooled weighted mean difference (WMD) and the 95\% CI were estimated using another software program. "I The contributions of each article to the primary outcome and the secondary outcome were weighed based on the sample size. Forest plots were produced to graphically represent the WMD and 95\% $\mathrm{CI}$ in primary and secondary outcomes for all included studies using periodontal sites as the unit of analysis. Heterogeneity among studies was assessed with $P$ value of $\chi^{2}$ test as well as $P$ test, and $P<0.05$ represents significant heterogeneity. The reporting of these meta-analyses adhered to the Preferred Reporting Items for Systematic Review and MetaAnalyses (PRISMA) statement. ${ }^{16}$ In addition, funnel plots were used to assess the presence of publication bias.

\section{RESULTS}

A flowchart of the screening process is presented in supplementary Figure 1 in online Journal of Periodontology. The searches from the four databases resulted in a total of 2,641 citations; after eliminating duplicates, 175 unique citations remained. Further review of the titles and abstracts resulted in 30 papers in full-text evaluation for eligibility. Of these studies, 22 articles ${ }^{11,12,17-36}$ were excluded, and eight articles $^{4-8,10,13,37}$ met the inclusion criteria. The reasons for exclusion are listed in supplementary Table 1 in online Journal of Periodontology.

The $\kappa$ value for inter-reviewer agreement of the included studies was 0.93, indicating an almost perfect agreement between the two reviewers according to the criteria of Landis and Koch. ${ }^{38}$ The features of the included studies are presented in Table 1 .

\section{Design and Features of Included Studies}

Of the eight included studies, six RCTs ${ }^{4-8,13}$ applied split-mouth design in performing the treatments, one $\mathrm{RCT}^{10}$ assigned patients into two treatment groups (surgical and non-surgical), and one study ${ }^{37}$ was a quasi-experiment $(\mathrm{QE})$. Regarding surgical treatments, seven RCTs ${ }^{4-8,10,13}$ performed MWF, three RCTs $^{5,6,8}$ performed OS, two studies ${ }^{13,37}$ performed OFD, and one study ${ }^{8}$ used SC. All of the included studies performed SRP as the non-surgical periodontal treatment. In addition, one study ${ }^{6}$ included coronal scaling (CS) as a non-surgical intervention. All patients received regular periodontal maintenance (supportive periodontal therapy [SPT]) every 3 to 6 months after the therapy.

\section{Risk of Bias Assessment}

The results of risk of bias assessment for the included RCTs are summarized in supplementary Table 2 . All of the included studies were considered to have high risk of bias.

\section{Meta-Analysis Results}

The data were stratified into three categories by initial PD. These consisted of 1 ) shallow (1 to $3 \mathrm{~mm}$ ); 2) moderate (4 to $6 \mathrm{~mm}$ ); and 3) deep ( $\geq 7 \mathrm{~mm}$ ) groups.

CAL changes. In 1 - to 3-mm PD, both non-surgical and surgical periodontal therapy resulted in loss of CAL: SRP, MWF, and OS resulted in (mean [range]) $23.2 \%$ (10.6\% to $43.5 \%$ ), $39.4 \%$ (22.9\% to $58.9 \%$ ), and $61.39 \%$ CAL loss, respectively. In 4 - to $6-\mathrm{mm} \mathrm{PD}$, SRP, MWF, OS, and OFD resulted in $8.4 \%$ (2.8\% to $22.6 \%), 6.5 \%$ (1.3\% to $27.2 \%), 5.22 \%$, and $7.58 \%$ CAL gain, respectively. In PD $\geq 7 \mathrm{~mm}, \mathrm{SRP}, \mathrm{MWF}$, and OS resulted in $9.8 \%$ (1.3\% to $47 \%$ ), $14.2 \%$ (3.2\% to 45.3\%), and 9.38\% CAL gain, respectively.

PD reduction. In 1 - to $3-\mathrm{mm} P D$, SRP resulted in increased mean (range) PD of $2.5 \%(0.5 \%$ to $11 \%)$, MWF resulted in increased mean (range) PD of 3.3\% $(0.8 \%$ to $12.9 \%)$, and OS resulted in mean PD reduction of $6.3 \%$ (2.6\% to $14 \%$ ). In 4 - to 6 - $\mathrm{mm} \mathrm{PD,}$ both surgical and non-surgical treatment modalities resulted in mean (range) PD reduction: SRP by $18.7 \%$ (12.9\% to $26.3 \%$ ), MWF by $25.4 \%$ (18.8\% to $33.5 \%$ ), and OS by $30.8 \%$ (21.9\% to $41.4 \%$ ). In $\geq 7-\mathrm{mm} \mathrm{PD}$, SRP, MWF, OS, and OFD resulted in mean (range) PD reduction of $21.6 \%$ (13.4\% to $32.9 \%$ ), $33.1 \%$ (24.3\% to $43.4 \%), 42.8 \%$ ( $29.4 \%$ to $57.4 \%$ ), and $41.8 \%$, respectively. The outcomes of the included studies are summarized in Table 2.

Surgical versus non-surgical periodontal therapy. In shallow PD (1 to $3 \mathrm{~mm}$ ), OS had greater mean PD reduction than SRP, with WMD of $0.02 \mathrm{~mm}(95 \% \mathrm{Cl}$ 0.12 to $0.23 \mathrm{~mm}, P<0.05)$; however, SRP resulted in less CAL loss than OS and MWF, with WMD of -0.30 $\mathrm{mm}(95 \% \mathrm{Cl}-0.48$ to $-0.12 \mathrm{~mm}, P<0.05)$ and -0.22 $\mathrm{mm}(95 \% \mathrm{CI}-0.38$ to $-0.06 \mathrm{~mm}, P<0.05)$, respectively.

In 4- to 6-mm PD, MWF resulted in higher PD reduction than SRP, with WMD of $0.35 \mathrm{~mm}$ (95\% CI 0.20 to $0.51 \mathrm{~mm}, P<0.05$ ) (Fig. 1). However, the WMD of CAL gain was $-0.29 \mathrm{~mm}(95 \% \mathrm{CI}-0.36$ to $-0.22 \mathrm{~mm}$, $P<0.05$ ) (Fig. 2), favoring SRP. In addition, the WMD of CAL between SRP and OS was $-0.34 \mathrm{~mm}(95 \% \mathrm{CI}$ -0.57 to $-0.12 \mathrm{~mm}, P<0.05$ ), favoring SRP (see supplementary Fig. 2 in online Journal of Periodontology). No significant difference in the reduction of PD was noted in between OS and SRP (see supplementary Fig. 3 in online Journal of Periodontology).

In PD $\geq 7 \mathrm{~mm}$, OS resulted in statistically significantly higher PD reduction than SRP, with WMD of

If Review Manager, v.5.3., The Nordic Cochrane Centre, The Cochrane Collaboration, Copenhagen, Denmark. 


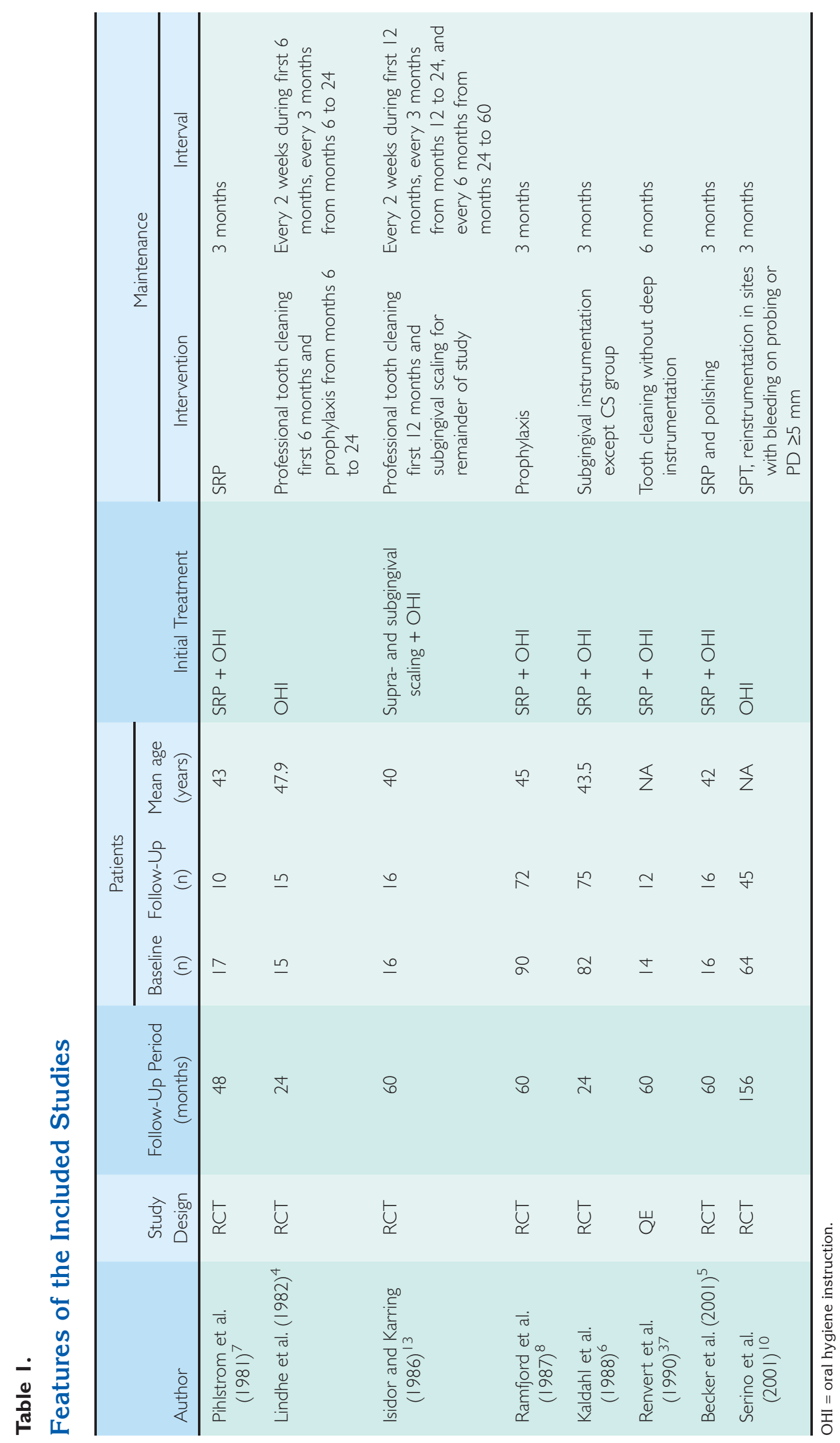


Table 2.

\section{PD Reduction and CAL Changes of Each Intervention}

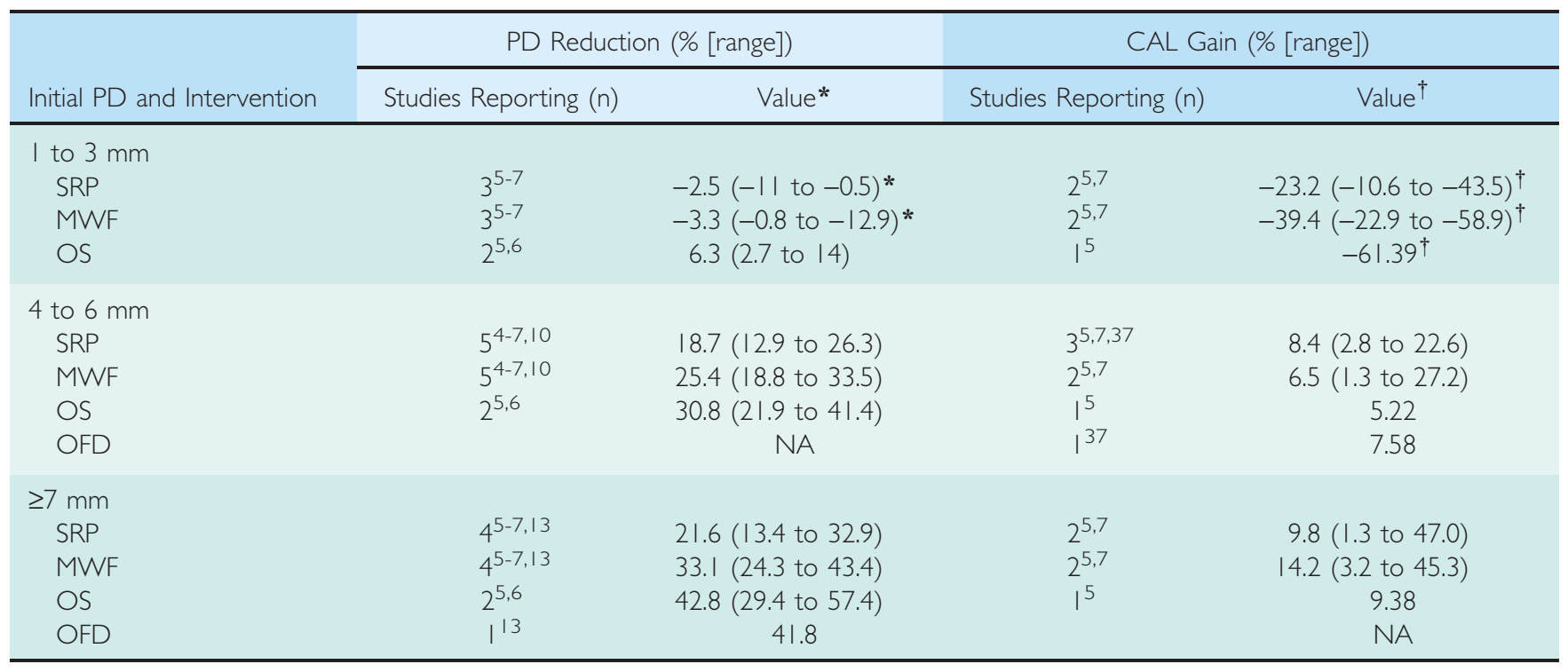

* Negative value represents PD increase.

$\dagger$ Negative value represents CAL loss.

$0.83 \mathrm{~mm}$ (95\% CI 0.10 to $1.57 \mathrm{~mm}, P<0.05)$ (Fig. 3). There was no statistically significant difference in PD reduction between MWF and SRP (see supplementary Fig. 4 in online Journal of Periodontology). Regarding CAL, there was less CAL loss after nonsurgical therapy. The WMD between SRP and MWF was $-0.38 \mathrm{~mm}(95 \% \mathrm{CI}-0.73$ to $-0.03 \mathrm{~mm}, P<0.05)$ (see supplementary Fig. 5 in online Journal of Periodontology), and the WMD between SRP and OFD was $-0.60 \mathrm{~mm}$ (95\% CI -0.93 to $-0.27 \mathrm{~mm}$, $P<0.05)$. OS and SRP resulted in similar CAL gain (see supplementary Fig. 6 in online Journal of Periodontology). Table 3 presents the summary of surgical and non-surgical therapy comparison. The publication bias of each comparison was evaluated with funnel plots (see supplementary Figs. 7 to 14 in online Journal of Periodontology).

\section{DISCUSSION}

\section{Summary of Main Findings}

The present review study demonstrates the long-term effect of surgical and non-surgical periodontal therapy in shallow, moderate, and deep PD. In shallow $P D$, both non-surgical and surgical treatment resulted in loss of CAL.

In moderate PD, MWF had statistically significant higher PD reduction than SRP. However, when CAL is considered, surgical therapy resulted in significantly greater attachment loss than SRP 1 year after surgery, and it was associated with significant loss of attachment from baseline at 2 years. Thus, in managing 4- to 6-mm moderate PD, surgical therapy should be considered carefully because of its disadvantage in CAL. ${ }^{33}$ No statistically significant difference of PD reduction was found between SRP and OS in initially moderate PD.

In deep ( $\geq 7 \mathrm{~mm}$ ) PD, OS had statistically significantly higher PD reduction than SRP. Meta-analysis failed to show significant PD reduction with SRP and MWF. When the available raw data of the included studies were combined, different results were seen. OS therapy resulted in the greatest PD reduction, followed by MWF and SRP, regardless of initial PD. With respect to CAL, OS had the highest CAL loss in shallow PD, followed by MWF and SRP. In moderate PD, OS had the highest CAL gain, followed by MWF and SRP. In deep PD, MWF achieved higher CAL gain than SRP and OS. However, statistical analysis could not be performed due to the heterogeneity of the study designs.

\section{Risk of Bias of Included Studies}

Of the included studies, only one study ${ }^{5}$ provided details regarding the randomization method. None of the included studies provided methods used to conceal the allocation sequence and mask the participants and outcome assessment. Three studies ${ }^{6,8,10}$ were found to have incomplete outcome data. Thus, based on the criteria for judging publication bias, all of the included studies are considered to have high risk of bias.

\section{Summary of Previous Studies}

It has been suggested that the loss of connective tissue after intervention caused the CAL loss measured after 


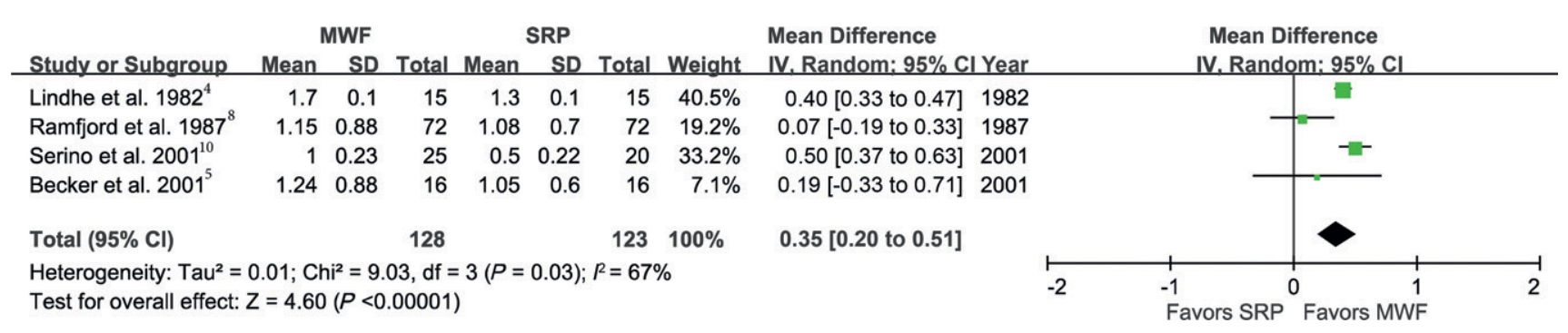

Figure I.

Meta-analysis for PD reduction between SRP and MWF in 4- to 6-mm PD.

\begin{tabular}{|c|c|c|c|c|c|c|c|c|c|c|c|}
\hline \multirow[b]{2}{*}{ Study or Subgroup } & \multicolumn{3}{|c|}{ MWF } & \multicolumn{3}{|c|}{ SRP } & \multicolumn{2}{|r|}{ Mean Difference } & \multirow{2}{*}{\multicolumn{3}{|c|}{$\begin{array}{l}\text { Mean Difference } \\
\text { IV. Random: } 95 \% \mathrm{Cl}\end{array}$}} \\
\hline & Mean & SD & Total & Mean & SD & Total & Weight & IV. Random: $95 \%$ Cl Year & & & \\
\hline Lindhe et al. $1982^{4}$ & -0.3 & 0.1 & 15 & 0 & 0.1 & 15 & $92.8 \%$ & $-0.30[-0.37$ to -0.23$] 1982$ & & & \\
\hline Ramfjord et al. $1987^{8}$ & -0.54 & 0.97 & 72 & -0.32 & 0.72 & 72 & $6.1 \%$ & $-0.22[-0.50$ to 0.06$] 1987$ & & & \\
\hline Becker et al. $2001^{5}$ & 0.3 & 1.16 & 16 & 0.28 & 0.65 & 16 & $1.1 \%$ & $0.02[-0.63$ to 0.67$] 2001$ & & & \\
\hline Total $(95 \% \mathrm{Cl})$ & & & 103 & & & 103 & $100 \%$ & $-0.29[-0.36$ to -0.22$]$ & 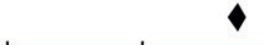 & & \\
\hline $\begin{array}{l}\text { Heterogeneity: } \mathrm{Tau}^{2}= \\
\text { Test for overall effect: }\end{array}$ & $\begin{array}{l}0.00 ; C h \\
Z=8.29\end{array}$ & $\begin{array}{l}\mathrm{i}^{2}=1 \\
(P<0\end{array}$ & $\begin{array}{l}18, \mathrm{df}= \\
.00001)\end{array}$ & $2(P$ & 55); & $R=0 \%$ & & & $\begin{array}{l}-1 \\
\text { Favors SRP }\end{array}$ & $P^{0}$ Favors MW & $\begin{array}{c}1 \\
N F\end{array}$ \\
\hline
\end{tabular}

Figure 2.

Meta-analysis for CAL gain between SRP and MWF in 4- to 6-mm PD.

\begin{tabular}{|c|c|c|c|c|c|c|c|c|c|c|c|c|}
\hline \multirow[b]{2}{*}{ Study or Subgroup } & \multicolumn{3}{|c|}{ os } & \multirow{2}{*}{\multicolumn{2}{|c|}{\begin{tabular}{ll}
\multicolumn{2}{c}{ SRP } \\
Mean $\quad$ SD
\end{tabular}}} & \multirow[b]{2}{*}{ Total } & \multirow{2}{*}{\multicolumn{2}{|c|}{$\begin{array}{ll} & \text { Mean Difference } \\
\text { Weight } & \text { IV. Random: } 95 \% \mathrm{CI} \text { Year } \\
\end{array}$}} & \multirow{2}{*}{\multicolumn{4}{|c|}{$\begin{array}{c}\text { Mean Difference } \\
\text { IV. Random: } 95 \% \mathrm{Cl}\end{array}$}} \\
\hline & Mean & SD & Total & & & & & & & & & \\
\hline Ramfjord et al. $1987^{8}$ & 3.53 & 1.69 & 26 & 2.92 & 2.17 & 28 & $50.4 \%$ & $0.61[-0.42$ to 1.64$] 1987$ & & & & \\
\hline Becker et al. $2001^{5}$ & 2.24 & 1.72 & 16 & 1.18 & 1.25 & 16 & $49.6 \%$ & $1.06[0.02$ to 2.10$] 2001$ & & & & \\
\hline Total $(95 \% \mathrm{Cl})$ & & & 42 & & & 44 & $100 \%$ & $0.83[0.10$ to 1.57$]$ & & & & \\
\hline $\begin{array}{l}\text { Heterogeneity: } \mathrm{Tau}^{2}= \\
\text { Test for overall effect: }\end{array}$ & $\begin{array}{l}0.00 ; C h \\
Z=2.23\end{array}$ & $\begin{array}{l}\mathrm{h}^{2}=0 . \\
3(P=0\end{array}$ & $\begin{array}{l}\text { 36, df = } \\
.03)\end{array}$ & $=1(P=$ & $=0.55)$ & $=0 \%$ & & & -4 & $\stackrel{-2}{\text { Favors SRP }}$ & ${ }^{0}$ Favors OS & 4 \\
\hline
\end{tabular}

Figure 3.

Meta-analysis for PD reduction between SRP and OS in $27-\mathrm{mm}$ PD.

treatment in 1 - to $3-\mathrm{mm}$ PD. ${ }^{12}$ Moreover, this loss may continue gradually during the maintenance phase in addition to the initial loss related to the treatment. ${ }^{8}$ In a 5-year study, OS was shown to have significantly greater PD reduction than SRP from 2 to 4 years in 4 - to 6-mm PD; however, these differences were not significant after 5 years. The authors concluded that changes in PD are caused by many variables. ${ }^{5}$ After SRP, there is resolution of inflammation, resulting in reorganization of connective tissue and raising resistance to apical penetration of the probe into the connective tissue. As a consequence, these changes may improve probing/attachment level. However, this phenomenon should not be interpreted as a gain in connective tissue attachment, but rather as changes in quality of gingival tissue due to resolution of inflammation. 5,6 Nonetheless, when effective SRP is difficult, as in the presence of furcation involvement or root groove/concavity, surgical therapy for access is indicated. ${ }^{19}$
A longitudinal study comparing the effect of flap surgery with and without osseous recontouring surgery demonstrated that OS was more effective in reducing and maintaining PD in deeper preoperative pockets than flap surgery without osseous recontouring. Both types of surgery reduced the PD initially; at 5-year follow-up, however, PD in the areas treated with flap surgery without osseous recontouring returned to preoperative levels, whereas OS resulted in stable PD and apically positioned tissue. Interproximal craters were eliminated and positive scalloped bone architecture could be achieved, preventing soft tissue rebound. ${ }^{24}$

In agreement with the present findings, several short-term studies showed similar results. ${ }^{11,12,28,31}$ In a 1 -year follow-up study, Becker et al. ${ }^{12}$ showed that surgical and non-surgical therapy significantly reduced 4- to 6-mm PD; however, MWF sites had greater PD reduction than SRP sites. Similarly, OS achieved significantly greater PD reduction compared to scaling in 
Table 3.

\section{Surgical and Non-Surgical Therapy Comparison}

\begin{tabular}{|c|c|c|c|c|}
\hline \multirow[b]{2}{*}{ Initial PD and Comparison } & \multicolumn{2}{|c|}{ PD Reduction (mm) } & \multicolumn{2}{|c|}{ CAL Gain (mm) } \\
\hline & Studies Reporting (n) & $P$ Value (mean [range]) & Studies Reporting (n) & $P$ Value (mean [range]) \\
\hline \multicolumn{5}{|l|}{ I to $3 \mathrm{~mm}$} \\
\hline SRP versus MWF & $2^{5,8}$ & $-0.01(-0.1 \mid$ to 0.09$)$ & $2^{5,8}$ & $-0.22(-0.38$ to -0.06$) *$ \\
\hline SRP versus OS & $2^{5,8}$ & $0.02(0.12 \text { to } 0.23)^{\dagger}$ & $2^{5,8}$ & $-0.30(-0.48$ to -0.12$)$ * \\
\hline SRP versus SC & $1^{8}$ & $0.02(-0.09$ to 0.13$)$ & $1^{8}$ & $-0.10(-0.29$ to 0.09$)$ \\
\hline \multicolumn{5}{|l|}{4 to $6 \mathrm{~mm}$} \\
\hline SRP versus MWF & $4^{4,5,8,10}$ & $0.35(0.20 \text { to } 0.5 \mathrm{I})^{\dagger}$ & $3^{4,5,8}$ & $-0.29(-0.36$ to -0.22$)$ * \\
\hline SRP versus OS & $2^{5,8}$ & $0.21(-0.01$ to 0.42$)$ & $2^{5,8}$ & $-0.34(-0.57$ to -0.12$)$ * \\
\hline SRP versus SC & $1^{8}$ & $-0.43(-0.65$ to -0.21$) *$ & & Not applicable \\
\hline SRP versus OFD & & Not applicable & $1^{37}$ & $0.10(-0.62$ to 0.82$)$ \\
\hline \multicolumn{5}{|l|}{$\geq 7 \mathrm{~mm}$} \\
\hline SRP versus MWF & $3^{5,8,13}$ & $0.36(-0.36$ to 1.09$)$ & $3^{5,8,13}$ & $-0.38(-0.73$ to -0.03$)$ * \\
\hline SRP versus OS & $2^{5,8}$ & $0.83(0.10 \text { to } 1.57)^{\dagger}$ & $2^{5,8}$ & $0.00(-0.85$ to 0.86$)$ \\
\hline SRP versus SC & $1^{8}$ & $-0.64(-1.74$ to 0.46$)$ & $1^{8}$ & $0.45(-0.82$ to 1.72$)$ \\
\hline SRP versus OFD & $1^{13}$ & $0.10(-0.11$ to 0.31$)$ & $1^{13}$ & $-0.60(-0.93$ to -0.27$)$ * \\
\hline
\end{tabular}

* $P<0.05$, favoring non-surgical therapy.

$\dagger P<0.05$, favoring surgical therapy.

the $\geq 7$-mm category. These findings were sustained at the 1-year follow-up. ${ }^{12}$ It has been reported that CAL and PD after periodontal treatment can be maintained in the long term with regular SPT every 3 months regardless of the patient's plaque control. ${ }^{39}$

In the previous systematic review, no comparisons were made between different types of surgical therapy and non-surgical therapy. ${ }^{9}$ In mild and moderate $\mathrm{PD}$, the current data show similar outcomes in CAL gain and PD reduction for surgical and non-surgical therapy compared to the previous review. ${ }^{9}$ However, in deep PD ( $\geq 7 \mathrm{~mm})$, these results show $0.4 \mathrm{~mm}$ less attachment loss after SRP, whereas a previous report ${ }^{9}$ demonstrated $0.2 \mathrm{~mm}$ more attachment gain obtained by access flap surgery. This difference might result from the varied study designs, inclusion/ exclusion criteria, or heterogeneity among the selected studies. Although WMD reached a statistically significant difference, the clinical significance needs to be further justified, since the difference might not be clinically detectable. Furthermore, this result is consistent with the study reported by Becker et al., ${ }^{5}$ which showed that although it did not reach a statistically significant difference, there was a trend of greater CAL loss in MWF compared to SRP in patients with initial PD $\geq 7 \mathrm{~mm}$.

Most studies were done before the turn of this century, and since then, knowledge of pathogenesis and risk factors has been expanded. Cigarette smoking and uncontrolled diabetes have been identified as worsening the long-term periodontal prognosis. ${ }^{40}$ Moreover, teeth with furcation involve- ment also have poorer prognoses and may continue to lose attachment even after treatment. ${ }^{41}$ Other factors, such as the presence of cervical enamel projections, palato-radicular grooves, loose interproximal contacts, overhanging restorations, and many others, have also been reported to be associated with the development of PD. ${ }^{42-45}$ Therefore, identifying and managing these contributing risk factors may improve treatment outcomes and ensure favorable long-term results.

Moreover, several other surgical techniques, such as papilla preservation, ${ }^{46}$ modified papilla preservation, ${ }^{47}$ simplified papilla preservation, ${ }^{48}$ minimally invasive surgical technique (MIST), ${ }^{49}$ and modified MIST, ${ }^{50}$ have been developed in an attempt to reduce surgical trauma and postoperative discomfort. These techniques have also been shown to have advantages in improving PD reduction and CAL gain in treating interdental intrabony defects with or without the additional use of regenerative materials. ${ }^{51,52}$ In addition, videoscope-assisted minimally invasive periodontal surgery was recently introduced for treating moderate PD and has shown favorable improvement in $\mathrm{PD}$ reduction and CAL. ${ }^{53}$

In the present study, data analysis shows that significantly greater attachment loss is achieved if surgical therapy is performed in shallow and moderate $\mathrm{PD}$, despite the advantage of $\mathrm{PD}$ reduction obtained by surgical therapy in moderate PD. Hence, it is suggested that surgical therapy will provide more advantages compared to non-surgical therapy if it is performed in deep PD. In accordance with these 
results, a critical PD of $5.4 \mathrm{~mm}$ has been proposed; it was recommended that surgical therapy is indicated in PD $\geq 5.4 \mathrm{~mm}$ and non-surgical therapy in PD from 2.9 to $5.4 \mathrm{~mm}^{3}$

Several limitations are noted in the current study: 1) the limited number of articles included (seven RCTs and one QE); 2) heterogeneity among the selected studies; 3) various study designs; 4) potential risk of bias; and 5) search performed only for articles written in English, resulting in potential publication bias. These limitations might increase the heterogeneity among comparisons in the metaanalysis. Therefore, these results should be interpreted cautiously, and additional well-designed, long-term RCTs should be performed to examine the clinical outcomes.

\section{CONCLUSIONS}

Within the limitations of this study, the following conclusions can be made: 1 ) in shallow PD, surgical therapy shows significantly more CAL loss than nonsurgical therapy; 2) in moderate PD, MWF shows significantly more PD reduction than SRP; however, there is significantly less CAL gain with surgical therapy compared to SRP; and 3) in deep PD, OS shows significantly higher PD reduction than SRP. More long-term RCTs that follow the CONSORT statement should be conducted to examine the clinical outcomes of surgical and non-surgical therapies.

These results imply the following in regard to clinical practice: 1) in initial moderate PD (4 to 6 $\mathrm{mm}$ ), SRP is preferable to surgical therapy because it might result in less CAL loss; and 2) if deep PD ( $\geq 7$ $\mathrm{mm}$ ) is present and indicated for surgical therapy, OS results in higher PD reduction than SRP.

\section{ACKNOWLEDGMENTS}

This study was supported by the Periodontal Graduate Student Research Fund, University of Michigan. The authors report no conflicts of interest related to this study.

\section{REFERENCES}

1. American Academy of Periodontology. Glossary of Periodontal Terms. Chicago, IL: American Academy of Periodontology; 2001.

2. Socransky SS, Haffajee AD, Cugini MA, Smith C, Kent RL Jr. Microbial complexes in subgingival plaque. $J$ Clin Periodontol 1998;25:134-144.

3. Heitz-Mayfield LJ, Lang NP. Surgical and nonsurgical periodontal therapy. Learned and unlearned concepts. Periodontol 2000 2013;62:218-231.

4. Lindhe J, Westfelt E, Nyman S, Socransky SS, Heijl L, Bratthall G. Healing following surgical/non-surgical treatment of periodontal disease. A clinical study. $J$ Clin Periodontol 1982;9:115-128.

5. Becker W, Becker BE, Caffesse R, et al. A longitudinal study comparing scaling, osseous surgery, and modified
Widman procedures: Results after 5 years. J Periodontol 2001;72:1675-1684.

6. Kaldahl WB, Kalkwarf KL, Patil KD, Dyer JK, Bates RE Jr. Evaluation of four modalities of periodontal therapy. Mean probing depth, probing attachment level and recession changes. J Periodontol 1988;59:783793.

7. Pihlstrom BL, Ortiz-Campos C, McHugh RB. A randomized four-years study of periodontal therapy. $J$ Periodontol 1981;52:227-242.

8. Ramfjord SP, Caffesse RG, Morrison EC, et al. 4 modalities of periodontal treatment compared over 5 years. J Clin Periodontol 1987; 14:445-452.

9. Heitz-Mayfield LJ, Trombelli L, Heitz F, Needleman I, Moles D. A systematic review of the effect of surgical debridement vs non-surgical debridement for the treatment of chronic periodontitis. J Clin Periodontol 2002; 29(Suppl. 3):92-102, discussion 160-162.

10. Serino G, Rosling B, Ramberg P, Socransky SS, Lindhe J. Initial outcome and long-term effect of surgical and non-surgical treatment of advanced periodontal disease. J Clin Periodontol 2001;28:910-916.

11. Isidor F, Karring $T$, Attström R. The effect of root planing as compared to that of surgical treatment. $J$ Clin Periodontol 1984;11:669-681.

12. Becker W, Becker BE, Ochsenbein C, et al. A longitudinal study comparing scaling, osseous surgery and modified Widman procedures. Results after one year. $J$ Periodontol 1988;59:351-365.

13. Isidor $F$, Karring $T$. Long-term effect of surgical and non-surgical periodontal treatment. A 5-year clinical study. J Periodontal Res 1986;21:462-472.

14. Higgins JP, Green S. Cochrane Handbook for Systematic Reviews of Interventions. Version 5.1.0 (updated March 2011). The Cochrane Collaboration, 2011. Available at: http://www.cochrane-handbook.org. Accessed August 29, 2014.

15. Schulz KF, Altman DG, Moher D; CONSORT Group. CONSORT 2010 statement: Updated guidelines for reporting parallel group randomized trials. Ann Intern Med 2010;152:726-732.

16. Liberati A, Altman DG, Tetzlaff J, et al. The PRISMA statement for reporting systematic reviews and metaanalyses of studies that evaluate health care interventions: Explanation and elaboration. J Clin Epidemiol 2009;62:e1-e34.

17. Forabosco A, Galetti R, Spinato S, Colao P, Casolari C. A comparative study of a surgical method and scaling and root planing using the Odontoson. J Clin Periodontol 1996;23:611-614.

18. Kaldahl WB, Kalkwarf KL, Patil KD, Molvar MP, Dyer JK. Long-term evaluation of periodontal therapy: I. Response to 4 therapeutic modalities. J Periodontol 1996;67:93-102.

19. Kalkwarf KL, Kaldahl WB, Patil KD. Evaluation of furcation region response to periodontal therapy. $J$ Periodontol 1988;59:794-804.

20. Kalkwarf KL, Kaldahl WB, Patil KD, Molvar MP. Evaluation of gingival bleeding following 4 types of periodontal therapy. J Clin Periodontol 1989;16:601-608.

21. Knowles JW, Burgett FG, Nissle RR, Shick RA, Morrison EC, Ramfjord SP. Results of periodontal treatment related to pocket depth and attachment level. Eight years. J Periodontol 1979;50:225-233.

22. Lindhe J, Nyman S. Scaling and granulation tissue removal in periodontal therapy. J Clin Periodontol 1985;12:374-388. 
23. Lindhe J, Westfelt E, Nyman S, Socransky SS, Haffajee AD. Long-term effect of surgical/non-surgical treatment of periodontal disease. J Clin Periodontol 1984; 11:448-458.

24. Olsen CT, Ammons WF, van Belle G. A longitudinal study comparing apically repositioned flaps, with and without osseous surgery. Int $J$ Periodontics Restorative Dent 1985;5:10-33.

25. Pihlstrom BL, McHugh RB, Oliphant TH, Ortiz-Campos C. Comparison of surgical and nonsurgical treatment of periodontal disease. A review of current studies and additional results after $61 / 2$ years. J Clin Periodontol 1983;10:524-541.

26. Pihlstrom BL, Oliphant TH, McHugh RB. Molar and nonmolar teeth compared over $61 / 2$ years following two methods of periodontal therapy. $J$ Periodontol 1984;55:499-504.

27. Ramfjord SP, Nissle RR, Shick RA, Cooper H Jr. Subgingival curettage versus surgical elimination of periodontal pockets. J Periodontol 1968;39:167-175.

28. Renvert S, Nilvéus R, Egelberg J. Healing after treatment of periodontal intraosseous defects. V. Effect of root planing versus flap surgery. J Clin Periodontol 1985; 12:619-629.

29. Rosling B, Nyman S, Lindhe J, Jern B. The healing potential of the periodontal tissues following different techniques of periodontal surgery in plaque-free dentitions. A 2-year clinical study. J Clin Periodontol 1976; 3:233-250.

30. Sigurdsson TJ, Holbrook WP, Karadottir H, Magnusdottir MO, Wikesjo UM. Evaluating surgical, non-surgical therapy in periodontic patients. J Am Dent Assoc 1994;125: 1080-1087.

31. Westfelt E, Bragd L, Socransky SS, Haffajee AD, Nyman $S$, Lindhe J. Improved periodontal conditions following therapy. J Clin Periodontol 1985;12:283293.

32. Wylam JM, Mealey BL, Mills MP, Waldrop TC, Moskowicz DC. The clinical effectiveness of open versus closed scaling and root planing on multi-rooted teeth. J Periodontol 1993;64:1023-1028.

33. Hill RW, Ramfjord SP, Morrison EC, et al. Four types of periodontal treatment compared over two years. $J$ Periodontol 1981;52:655-662.

34. Ramfjord SP, Knowles JW, Nissle RR, Shick RA, Burgett FG. Longitudinal study of periodontal therapy. $J$ Periodontol 1973;44:66-77.

35. Ramfjord SP, Knowles JW, Nissle RR, Burgett FG, Shick RA. Results following three modalities of periodontal therapy. J Periodontol 1975;46:522-526.

36. Tan AE. Longitudinal periodontal treatment outcomes in private practice. Ann $R$ Australas Coll Dent Surg 2002;16:84-92.

37. Renvert S, Nilvéus R, Dahlén G, Slots J, Egelberg J. 5year follow up of periodontal intraosseous defects treated by root planing or flap surgery. J Clin Periodontol 1990;17:356-363.

38. Landis JR, Koch GG. The measurement of observer agreement for categorical data. Biometrics 1977;33: $159-174$

39. Ramfjord SP, Morrison EC, Burgett FG, et al. Oral hygiene and maintenance of periodontal support. $J$ Periodontol 1982;53:26-30.
40. McGuire MK, Nunn ME. Prognosis versus actual outcome. II. The effectiveness of clinical parameters in developing an accurate prognosis. J Periodontol 1996; 67:658-665.

41. McFall WT Jr. Tooth loss in 100 treated patients with periodontal disease. A long-term study. J Periodontol 1982;53:539-549.

42. Hou GL, Tsai CC. Relationship between periodontal furcation involvement and molar cervical enamel projections. J Periodontol 1987;58:715-721.

43. Hou GL, Tsai CC. Relationship between palato-radicular grooves and localized periodontitis. J Clin Periodontol 1993;20:678-682.

44. Hancock EB, Mayo CV, Schwab RR, Wirthlin MR. Influence of interdental contacts on periodontal status. J Periodontol 1980;51:445-449.

45. Lang NP, Kiel RA, Anderhalden K. Clinical and microbiological effects of subgingival restorations with overhanging or clinically perfect margins. J Clin Periodontol 1983;10:563-578.

46. Takei HH, Han TJ, Carranza FA Jr., Kenney EB, Lekovic V. Flap technique for periodontal bone implants. Papilla preservation technique. J Periodontol 1985;56:204-210

47. Cortellini P, Prato GP, Tonetti MS. The modified papilla preservation technique. A new surgical approach for interproximal regenerative procedures. J Periodontol 1995;66:261-266.

48. Cortellini P, Prato GP, Tonetti MS. The simplified papilla preservation flap. A novel surgical approach for the management of soft tissues in regenerative procedures. Int J Periodontics Restorative Dent 1999;19: 589-599.

49. Cortellini $P$, Tonetti MS. A minimally invasive surgical technique with an enamel matrix derivative in the regenerative treatment of intra-bony defects: A novel approach to limit morbidity. J Clin Periodontol 2007; 34:87-93.

50. Cortellini P, Tonetti MS. Improved wound stability with a modified minimally invasive surgical technique in the regenerative treatment of isolated interdental intrabony defects. J Clin Periodontol 2009;36:157-163.

51. Graziani F, Gennai S, Cei S, et al. Clinical performance of access flap surgery in the treatment of the intrabony defect. A systematic review and meta-analysis of randomized clinical trials. J Clin Periodontol 2012;39: 145-156.

52. Cortellini P, Tonetti MS. Clinical and radiographic outcomes of the modified minimally invasive surgical technique with and without regenerative materials: A randomized-controlled trial in intra-bony defects. J Clin Periodontol 2011;38:365-373.

53. Harrel SK, Abraham CM, Rivera-Hidalgo F, Shulman JD, Nunn ME. Videoscope-assisted minimally invasive periodontal surgery (V-MIS). J Clin Periodontol 2014; 41:900-907.

Correspondence: Dr. Hom-Lay Wang, 1011 North University Ave., Ann Arbor, MI 48109-1078. Fax: 734/936-0374; e-mail: homlay@umich.edu.

Submitted March 9, 2015; accepted for publication June 3, 2015. 